\title{
The Policy Relevance of Models in World Politics
}

\author{
RAYMOND TANTER ${ }^{1}$ \\ Department of Political Science, University of Michigan
}

\begin{abstract}
When the student of politics is a poet, his simulations of international relations are works of art, constructions that fulfill aesthetic needs. When the student of politics is a social scientist, his simulations of international processes are theories that need verification like other claims to knowledge. When the scholar is a policy influencer, he seeks to make application of simulations so that he may guide the affairs of states and international organizations in directions he values and wishes to achieve [Guetzkow, 1968, p. 202, emphasis added].
\end{abstract}

\section{Introduction}

The opening statement by Guetzkow highlights the many roles played by the student of politics. The poet of politics

1. Acknowledgements to Hazel Markus for research assistance, Clinton Fink, Gretchen Fei, Stephen Shaffer, Richard Ullman, Oran Young, and Robert Young for critique, as well as Patricia Armstrong and Marian Oshiro for typing and editing, and the support of ONR contract N00014-67-0181-0042 ARPA Order No. 1411. The opinions expressed in this essay are those of the author and do not reflect the views of the Advanced Research Projects Agency or any other agency of the US government. certainly plays an important role. Indeed he may be a major source of enlightenment for further scientific inquiry. Similarly the student of politics as a scientist has a valuable role. He can build on the poet's contribution, yet adhere to criteria for scientific concept formation and thus build fruitful theory. The concerns of the scholar as policy influencer, however, are slightly different. Policy influencers should address the problem of how their product can be applied to influence policy makers and policy analysts. $^{2}$ Guetzkow suggests a criterion of relevance that the scholar as policy influ-

2. The present essay distinguishes between policy influencer, policy maker, and policy analyst. An influencer is a scholar outside of government who is trying to apply his knowledge in order to validate it and influence policy in desired directions. A policy maker on the other hand is a decision maker or governmental problem solver, e.g in the US the rank of deputy assistant secretary and above. A policy analyst is a staff person to the problem solver, e.g. an intelligence analyst who has a great need for substantive information systems to retrieve, manipulate, model, and estimate information concerning the future (cf. Hilliker, 1971). The scholar as influencer normally works through the analyst rather than directly with the policy maker himself. Thus the analyst often stands at the interface between the scholar and decision makers. 
encer may use as a test for his product, to wit, whether his model allows one to guide the affairs of state in desired directions.

Guetzkow's criterion suggests that a model's implications must be perceived as feasible by those in command prior to its application. Moreover, the criterion implies that the model must address problems perceived to be relevant by the policy makers and analysts themselves. Feasibility and applicability to current policy needs often are criteria for evaluating policy relevance. For example, Whiting (1972) states that ". . . applicability to perceived policy needs is half the battle. Feasibility constitutes the other half." Whiting, however, is pessimistic about the ability of scholars to cope with the applicability-feasibility issue. Regarding the United States, for example, Whiting states that

\begin{abstract}
Washington is far more insular in its perceptions and conservative in its estimates of the possible than most academicians appreciate. If professors are criticized for living in an ivory tower, the Washingtonian inhabits a labyrinthine honeycomb with the queen bee directing her court as they, in turn, the hive [1971, p. 13].
\end{abstract}

Whiting's pessimistic assessment of the extent to which scholars can fertilize the policy-queen suggests that one focus attention on the queen, her court, and its processes. In this regard, what can the scholar do to focus attention and involve himself in the policy process in order to influence it? To address this question realistically, consider four assumptions about policy execution and how one influences policy. First, elites and organizations try to dominate policy decisions in order to gain bureaucratic advantage and protect themselves against other organizations and elites. It is reasonable to assume that policy makers generally will not be receptive to research which generates options suggesting that policy makers should act in a manner contrary to their own perceived interests. Halperin (1971, p. 89) notes that options are unlikely to be advanced or accepted if they: (1) involve cooperation between organizations; (2) require an organization to alter its structure; or (3) perform extraneous missions. Policy makers, however, are receptive to knowledge concerning the implementation of their goals if the knowledge is consistent with their organizational interests.

A second important assumption about policy execution and influence is that government does not operate as a unitary actor. For example, Halperin (1971) suggests that in seeking to understand why a government such as the United States adopts a particular policy or takes a specific action, one should assume that the participants in the policy process look at issues differently and rarely agree on what should be done. In support of the heterogeneous nature of government, Halperin describes the line-up of interests and factions when Charles Hitch, then Comptroller of the Department of Defense, recommended cancellation of the Skybolt program in 1964 (also cf. Neustadt, 1970). Skybolt, a missile designed to carry a nuclear warhead and to be fired from strategic bombers, is the weapon system Eisenhower promised to share with Great Britain in 1960. Each official or bureaucracy concerned with the Skybolt decision saw the issue differently, based on diverse organizational interests. Hitch, for instance, viewed the Skybolt issue as a budget matter. He thought that Skybolt should be cancelled since: (1) its first test launches had been unsuccessful; and (2) it was unnecessary, given Hitch's strategic calculations. The Air Force, however, defended Skybolt and saw the proposal to cancel it as a threat to one of its fundamental organizational missions involving strategic bombers. Secretary of State Dean Rusk, on the other hand, saw cancella- 
tion of Skybolt as a threat to US-British relations. In addition, Robert McNamara, Secretary of Defense, and the President had other interests and perceptions and took still different stands on the issue. In short, US security policy regarding Skybolt emerged through the clash and compromise of bureaucratic interests. Organizations fought to preserve their autonomy, roles, and budgets.

The fact that government is composed of many individuals and bureaucracies which often take diverse stands on any given issue works in favor of a potential policy influencer. If a scholar has research bearing on questions that policy makers have posed, he should find some governmental participant who holds policy preferences compatible with those suggested by his research findings. In essence, influencing policy involves seeking out an organization or individual whose preferences require the particular model or research findings that a scholar has to offer. If a policy influencer is to be successful and guide the affairs of state in desired directions, he must locate an organization which shares or almost shares his position, then persuade the organization to adopt his model or findings.

In a related vein Rapoport (1970) discusses the application of peace research. $\mathrm{He}$ claims, however, that no government organizations are available to translate the findings of peace research into action directed toward the solution of war-peace type problems. While this may be true for the findings of some peace research, there are certainly institutions already in the government which could translate research findings into action, if the policy influencer could demonstrate how his findings served organizational interests. Peace researchers however may take a moral stance that prohibits them from becoming soiled by the "devils" in government. As a result, they may be relatively uninformed about the details of conflicts between nations because such information is classified. These researchers also may lack information about the points of leverage within governments for applying peace research.

To accuse one's fellow scholars of being uninformed is a very serious charge indeed, and thus the author takes this opportunity to document the charge. Peace research scholars generally opposed US involvement in the Indochina War, especially beginning in 1961 with the Kennedy administration. How many peace researchers bothered to learn from the inside something about the policy process that culminated in Vietnam? How many attempted to study the Vietnam War itself as an object of scholarly inquiry? Very few dared to join the government to learn about the policy process from the inside. Glancing at the past issues of the Journal of Conflict Resolution, Journal of Peace Research, Papers of the Peace Research Society (International), Journal of Social Issues, and others, one finds only a very small number of articles devoted to Vietnam directly or indirectly. ${ }^{3}$

When a courageous peace researcher, Waiter Isard, dared to edit a volume dealing with the Indochina War (1970), some of his colleagues (especially Europeans) attacked Isard for supporting US imperialism. Ridiculous! An essay in Isard's Papers that received vicious criticism for studying instead of condemning is the one by Milstein and Mitchell (1970).

The Milstein and Mitchell study is incredibly naive regarding the bureaucratic processes underlying many US policies, yet right on the button in focusing attention on action-reaction patterns among the belligerents. Their essay persuasively demonstrates the futility of the "peace through escala-

3. An issue by White (1966) is one of the few attempts to study the Vietnam War as an object of scholarly inquiry. See also Olsen and Jarvad, 1970; Galtung, 1971 ; Oppenheimer, 1964; Schmid, 1968; Schwartz, 1968; Wallace, 1971; and Kent, 1972. 
tion" policy of the Johnson administration. What did Milstein and Mitchell receive for their scholarship? Criticism from the left for serving the devil and attacks from the right for such uninformed procedures as calculating bombing rates without taking into account classified bombing in Laos, and using piastre values as indicators of public confidence in the Saigon regime without understanding the role of money changers in Saigon.

The naiveté of the Milstein and Mitchell study does not stem from their reluctance to involve themselves in the policy process. They tried to involve themselves without success. In this regard the present author introduced them to policy analysts working on Vietnam in the US government and used their work as a means of promoting a deescalatory US policy regarding Vietnam. Incorrect assumptions and a lack of classified data resulted in a failure to apply the "peace findings" of Milstein and Mitchell. It was not the absence of bureaucrats favoring a deescalatory policy that resulted in the failure to sell their peace products; rather it was the incorrect assumptions, lack of credible information, and the inability of social scientists to translate their jargon into generally understandable terms that prevented the peace products from being applied.

Vietnam notwithstanding, if a research question has been formulated from the point of view of the policy maker, the findings can be implemented by an existing institution or the questions would not have been posed in the first place. In a related vein, consider Kent (1971) as he answers Rapoport: "The great majority of questions that are asked by peace researchers would not be of interest even if they were answered perfectly" ( $p$. 48). Research on problems which are not currently under consideration by some governmental organization or another has very little chance of being accepted. The research might be important at some future date, but it will not in any way influence or guide current policy. If direct influence on current policy is the goal, a researcher must pose his question from the point of view of the policy maker, taking organizational constraints and interests into account. He should ask what research would be most useful in dealing with the problem. He then must seek out an organization or individual who accepts and can act on these findings.

An alternative strategy might be to ignore the policy maker and focus on the objects of policy. For example, a scholar could have directed his models and findings regarding Vietnam to Third World forces who were being bombed in Indochina rather than to those who conducted the bombing. This strategy, however, is not viable for several reasons: (1) the models and findings of relevance here may relate to manipulables over which the bombers but not the bombed have some control; (2) the models and findings are understandable only to a small elite group, which stresses "rational decision-making" and scientific solutions; and (3) the policy influencer probably has even less access to the bombed than to the bombers.

Much of the existing peace research could be made policy relevant if it were presented in the manner proposed here. The implications of most peace research could be implemented through existing institutions; peace research does not require $a$ priori that radical changes be made in governmental structures, even though some peace researchers may have this impression. If new institutions are to be created, however, they should be of the type that would ease the communication process between the policy influencer and the policy maker. As Haas (in press) notes, institutions that facilitate communication are essential if peace researchers 
are to know what questions to ask and to conduct research that is both respectable academically and influential politically.

A third assumption now can be stated. Policy influencers can be in tune with government demands and responsive to government needs but in turn may be manipulated by the government. Kent (1971) agrees with this third assumption: "The peace researcher does risk being influenced, but that is the price of exerting influence."

The moral stance of many scholars prevents them from having intellectual intercourse with the queen bee and with members of her court. A "holier-than-thou" attitude often hinders the application of peace research, a curious situation indeed. Consider analogies with religion, health, and education. Should a minister ignore the sinners and only convert the already "saved"? Should a medical doctor ignore the sick and only try to heal the well? Should a teacher ignore the ignorant and only disseminate knowledge to the learned? No! To ignore the sinners, the sick, and the ignorant is to be morally neutral in the face of responsibilities corresponding to capabilities. Paraphrasing Dante, John F. Kennedy said that the hottest place in hell is reserved for those who are morally neutral in time of crisis.

A fourth assumption provides a rationale for the task and the goals of the policy influencer: by improving the information base of policy makers, a policy influencer ultimately can effect policy decisions in desired directions. Improving the information base for policy makers partly involves conducting research which is guided by questions they pose. ${ }^{4}$ The idea that government can be influenced implies a belief that

4. Admittedly requirements for theory construction may conflict with perceived policy needs. For example, a theorist may be interested only in explaining processes underlying a particular phe- the decision process can be improved, which may lead to increased chances for peace. The hope expressed here is the same as that of Pilisuk (1972) in his desire that "... international conflict may someday become a matter in which a free public exercises an international policy befitting the dignity of man" (p. 198). A policy influencer, as a member of a free public, can begin this process if he is willing to address the critical questions and to work within the constraints implied by the assumptions specified above.

Several attempts have been made to delineate the specific research tasks that scholars can perform to involve themselves in the policy process in order to influence it. The International Relations Committee of the Society for the Psychological Study of Social Issues (SPSSI) recently addressed this problem. A SPSSI report states that the scholar has the ability to supply organizing concepts which could lend coherence to decision processes and also tools to help policy analysts anticipate emerging problems. In this context models can be powerful vehicles for focusing attention on and facilitating involvement in the policy process. The SPSSI report notes that forecasting, diagnosis, and assessment also are roles of relevance to the policy process.

In another attempt to define how scholars may be effective in government, the author, Philip Burgess, and others at an International Studies Association-State Department Conference on Data Banks for International Studies developed a tentative description of problem solving and policy

nomenon. The policy maker, however, may be interested only in the likely outcomes of these processes. The theorist must be careful that he does not overlook the processes that constitute the basic objects for theory construction. The possibility that policy needs will cause a scholar to focus on "the wrong questions" is a risk one should be aware of as he seeks to be policy relevant. 
analysis functions. These functions are summarized in Table 1. As in the SPSSI report, the table lists the various roles a scholar or policy influencer can assume in attempting to participate in the policy process. The various information needs for each role are also specified. Note that the functions and needs of the academy and polity become blurred when one focuses on the tasks that can overlap both arenas. Using Table 1 as a starting point, it appears that there are many opportunities for scholarly involvement in the policy process (also cf. Hilliker, 1972).

This paper concentrates on models to illustrate what has been done and what yet must be done if policy influencers are to be effective. By confining this paper to models, the hope is to narrow the realm of research to be discussed so that specific criteria of policy relevance can be delineated and illustrated. The need for valid models in the policy process is best emphasized by an example. In the case of Indochina, US decision-makers who sought to intervene in the Indochina War based such intervention on at least two distinct and often contradictory approaches, both of which imply faulty models of the Indochina situation. One approach assumed that the US could intervene successfully if its program could "win the hearts and minds" of the people, e.g. by increasing their wealth through economic development.

There was little sympathy from the military for the so-called welfare approach to the Indochina War. Thus, while the welfare advocates focused on popular attitudes, the military emphasized the control of behavior, stressing military rather than economic assistance in order to provide for population control and territorial security. Economic development advocates, moreover, rightly condemned the military approach as not being relevant to the political conflict in Vietnam. Neither the welfare nor warfare approaches, however, worked well in Vietnam separately, and they were never combined adequately. In addition, both approaches overlooked aspects of the Indochina social and political situation which constrained the counterinsurgency and the conventional combat programs. (The relevant aspects of the Indochina situation have been "modelled" in the research of such scholars as Race (1973); also cf. Komer (1973) for an emphasis which combined economic and military approaches.)

In the present context models are a product of a systematic process of constructing knowledge, either by mostly deductive

\section{TABLE 1}

PROBLEM SOLVING AND POLICY ANALYSIS-ROLES, FUNCTIONS, AND NEEDS

\begin{tabular}{|c|c|c|}
\hline Roles & Functions & Information needs \\
\hline Evaluator or Diagnostician & Scorecard or program evaluation & $\begin{array}{l}\text { Program goals and discrepancy } \\
\text { indicators }\end{array}$ \\
\hline Planner & $\begin{array}{l}\text { Attention directing or problem } \\
\text { identification }\end{array}$ & $\begin{array}{l}\text { Early warning indicators under } \\
\text { alternative future costs }\end{array}$ \\
\hline Operator & $\begin{array}{l}\text { Problem solving or policy } \\
\text { making }\end{array}$ & $\begin{array}{l}\text { Options, costs, and benefits-both } \\
\text { foreign and domestic }\end{array}$ \\
\hline Analyst & $\begin{array}{l}\text { Case comparison and system } \\
\text { structure analysis }\end{array}$ & $\begin{array}{l}\text { Memory of actions and reactions of } \\
\text { foreign environment }\end{array}$ \\
\hline Scientist & $\begin{array}{l}\text { Estimation of system state and } \\
\text { rate parameters for explanation }\end{array}$ & Model-derived indicator system \\
\hline Forecaster & Forecasting & $\begin{array}{l}\text { Outputs from analysis and model } \\
\text { building }\end{array}$ \\
\hline
\end{tabular}


or primarily inductive strategies. ${ }^{5}$ Deductive modelling emphasizes formal construction of axioms, a specification of their interrelationships, and the derivation of empirically testable conclusions (cf. Riker, 1962; Richardson, 1960a; Frohlich, Oppenheimer, and Young, 1971). Inductive modelling, on the other hand, stresses the discovery of empirical regularities, a development of possible explanations of such patterns, and tests of hypotheses to provide further validation of the regularities (cf. Richardson, 1960b; Rummel, 1969; Singer and Small, 1969; Alker, 1969). Whether the strategies are mainly deductive or primarily inductive, the process of model building should be distinguished from the product of model building. The criteria of policy relevance discussed below mainly address the product of model building.

\section{Criteria for Policy Relevance of Models: Control and Confidence}

In any discussion of policy relevance several criteria are usually implicit. One criterion states that a model must be accept-

5. If a body of theory about world politics were developed already, there would be no need to use the unfortunate dichotomy of deductive and inductive strategies. The relatively undeveloped state of theory in world politics is widely accepted (cf. Young, 1972). It is only in the last twenty years that modelling and the use of rigorous research methods have been applied seriously to developing theory. Given this short history of systematic theory construction, it is necessary to attempt a mix of deductive and inductive strategies. Also, this essay distinguishes model from theory in the following sense. A model is a set of concepts that abstracts a portion of the world for explanatory possibilities. A model may or may not be a valid representation of the underlying process, and the model may be deductively or inductively based. A theory, however, is a set of propositions linked into a deductive system. Thus there is no such animal as "inductive theory." able or compatible with the dominant value framework of the policy maker. Value, ethical, and moral considerations define the range within which policy influencers can operate. Unless a model falls within this range, it cannot hope to be policy relevant. Models which allow for a greater number of alternatives within this range are more policy relevant.

Once again it should be noted that a government does not function as a monolithic actor and consequently there are many different value frameworks represented. A task of the policy influencer is to seek out an individual or an organization which most closely embodies the value system underlying his particular model. If a policy influencer cannot find such an individual or organization, then he is faced with the more difficult task of changing or modifying values by employing his only unique qualification-systematic knowledge. A policy influencer may often have to deal with those who hold values antithetical to his own. In addition, policy influencers have only limited control over how policy makers use their fudings. Loss of control over how one's knowledge will be used is one of the several costs of attempting to influence the policy process. If however useful policy recommendations are to be made as a result of policy influencers' models, the links between the research and dominant values of the system should be specified (cf. Nicholson, 1970, p. $158 \mathrm{ff}$.).

Another criterion of policy relevance appears obvious but is very seldom made explicit. This criterion states that for a model to be relevant it must address the phenomena about which policies are to be developed and about which decisions are to be made. This criterion, discussed in terms of feasibility and applicability by Whiting (1972), is often taken for granted when in fact it is rarely met. The criterion implies 
more than a mere similarity in topic between the model and the policy question; rather the criterion implies a direct link between the policy influencer's model and a policy decision. Kent (1971) makes the same point, stating that: "One criterion for assessing the policy relevance of any piece of research is to ask if any concrete decision problem can be imagined in which the findings of the research might affect the choice that would be made" (p. 49). The feasibility-applicability criterion will be employed generally throughout the paper in evaluating the policy relevance of various models. For each type of model discussed, examples will be given of how the model could or could not be applied to a policy decision problem. A final overall criterion is the degree to which a model is valid. That is, the model should be a good representation of the underlying process so that adequate predictions can be made.

Two specific criteria which will be applied systematically to the various models are: (1) the degree to which policy makers will perceive they have control over predictors in the model; and (2) the degree of confidence policy makers will have in the model's implications.

In this paper an indicator of control is perceived manipulability. Indicators of confidence are: (a) the degree of the model's deductive power and empirical applicability; and (b) the extent to which the validation of the model employs multiple streams of evidence.

If a policy maker values a goal highly, he may perceive that he can manipulate the factors that might affect goal achievement. The degree to which a policy maker feels he can and should manipulate variables in a model may be a result of the value he places on the goal, the cost of intervention, and his capability to intervene. ${ }^{6}$ A highly valued

6. The present essay uses the term manipula ble in the sense of perceived control, given the goal, low expected cost of intervention, coupled with a perceived capability to intervene successfully, may be a dangerous situation. This situation may lead a policy maker to perceive that he can manipulate the factors which he hopes will effect the desired end, irrespective of the probability that the manipulation of these factors will effect the goal.

For example, in relation to expected costs of intervention, US policy makers placed a high value on "winning" the Vietnam War in 1965-1968. They had control over a great capability for intervention; perhaps as a result they incorrectly assumed that the actual determinants of the Vietnam War's outcome were under US control. US policy makers may have been more interested in manipulating variables based on a theoretically invalid model than acknowledging the inability to determine Vietnam outcomes.

If the policy maker places a high value on winning in relation to costs, he may decide that manipulables need not be valid predictors of the desired outcomes as long as they permit him to act; taking some action may be, in the short run, politically wise although theoretically foolish. As Gallup (1962) stated, "I would say that any drop in popularity is likely to come from a President's inaction in the face of an important event. Inaction hurts a President more than anything else. A President can take some action, even a wrong one, and not lose his popularity" (p. 34). If action is theoretically unwarranted, however, it would be politically foolish in the long-term, as witnessed by the fall of President Johnson in 1968 as a result of Vietnam.

values, costs, and capabilities of a particular policy maker. In this sense most variables are ultimately manipulable. The crucial questions then are the values, costs, and capabilities of the decision maker or scholar. Hereafter, however, the term manipulable may appear without these qualifiers, but manipulability always refers to relative manipulability. 
Regarding the cost and capability for intervention, the policy maker may perceive that some variables are manipulable only at great costs. For example, consider an article by Choucri and North (1972). One of their goals is "... to distinguish between those variables that are readily manipulable and those that are less so or are manipulable at relatively higher costs ..." (p. 5). In discussing possible determinants of warfare Choucri and North suggest that policy makers perceive that they can manipulate a factor such as a defense budget at less cost than they can change attributes such as population size or technological capability of their nations. Choucri and North find that demographic factors may be more important long-term determinants of warfare than short-term fluctuations in defense budgets. That is, the "more costly to manipulate" demographic factors explain a greater percentage of the variation in international violence than do the less costly to manipulate defense expenditures. Since foreign policy decision makers often are unaware of such connections, and in any event the demographic factors seem to be less subject to their immediate control than the defense expenditures, the tendency is for them to manipulate defense budgets and ignore demographic factors (see also Burgess, 1970).

Kent (1971) also discusses manipulability, stating that it is much more useful to know that wars may be caused by arms races than that wars are the result of man's aggressive nature. Arms races can be modified, while man's nature is more clearly outside the immediate domain of the policy influencer. Models which suggest factors that a policy maker can control are more relevant than those models that are based on noncontrollable factors. Once manipulables have been specified, a next step is action based on these manipulable factors-at which point the policy influencer can begin to succeed.
The second specific criterion of policy relevance employed in this essay is the degree of confidence a policy maker will have in a model's implications. If a model combines deductive power with applicability, there should be more confidence in its implications. Models are likely to be accepted as relevant if they yield conclusions which are deductively based yet perceived to be applicable to the world of the policy maker. Deductive models frequently sacrifice empirical fit for logical closure; on the other hand, models based on inductive strategies often sacrifice logical closure for empirical applicability. Logical closure increases one's confidence in the validity of a derived proposition. Thus a policy relevant deductive model is likely to yield implications which are believed by policy makers. If a deductive model does not fit the empirical situation, however, this may decrease the confidence a policy maker has in its implications. Hence a second criterion of policy relevance in this essay is that models should combine deductive power with empirical applicability.

The formal structure of deductive models, e.g. of conflict behavior, can be developed and then partially validated by testing the implications in controlled laboratory experiments illustrating a deductive-inductive mix. The value of a deductive model of conflict behavior is based on the level of generality it possesses due to its elegance-its freedom from having to take into account the idiosyncracies of exogenous factors. A price may be paid, however, for this elegance. Models structured in a formal, deductive manner may be inadequate by themselves to explain most, if not all, aspects of human conflict behavior. For the concepts and insights of a deductive model of conflict behavior to lead to a fruitful theory, they must be integrated into a broader framework, that is, by including 
nonaxiomatic empirical considerations.

On the other hand, inductive studies (e.g. correlational studies employing aggregate data) are in some sense "closer" to actual conflict situations than a deductive model. These studies also are not adequate for explaining conflict behavior. In these correlational studies causal patterns often are not specified explicitly, and therefore in attempting to manipulate variables one may not achieve the desired goals. Or the macrolevel variables being studied (e.g. urbanization, economic development, etc.) may be perceived by the policy influencer as virtually beyond manipulation-at least in the short-run (cf. Feierabend, 1969; Gurr, 1968, 1970).

The author and Markus have developed a model of conflict behavior which combines the results of empirical research within a framework of a deductive model (Markus and Tanter, 1972; also cf. Axelrod, 1970). The deductive model assumes that actors in a conflict situation weigh the costs and benefits of various possible actions before undertaking any particular step. Actors in a conflict situation also may realize benefits which are independent of the specific goals or aims over which the conflict has arisen.

Empirical research suggests that psychological benefits such as catharsis and feelings of group identity, efficacy, self-esteem, etc., may result from participation in conflict, regardless of whether the more conscious goals of the conflict are achieved. Moreover if one adheres to the ideas of ethologistswhich are often based on inductive research dealing with animal behavior-conflict may be a necessary and inevitable process quite independent of strategic considerations. The overall conflict model, therefore, is based on the idea that along with more conscious aims other goals-psychological and even possibly instinctive in nature-may be maximized at different points in the conflict process.
When the findings of empirical investigations can enlarge the scope of a deductive model, it usually increases the model's policy relevance. In the conflict model example above, the results of the empirically oriented studies could be used to modify the deductive model. Thus a model that reflects the empirical regularities that have been observed in these studies combines deductive power with empirical applicability.

The degree of confidence a policy maker has in a model's implications also stems from the utilization of multiple streams of evidence in the model building enterprise. Models should utilize multiple streams of evidence in order to increase the probability of valid inferences. Models which are linked to single types of evidence have more threats to their validity than those grounded in multiple bases of evidence. For example, models based on experimental evidence alone may be externally invalid but internally valid, e.g. there may be threats to the generalizability of the model from the laboratory to the external referent, but the laboratory controls decrease threats to internal validity. On the other hand, models based upon sample survey data may be externally valid but internally invalid. The survey based models may use randomly selected samples of large populations in order to increase the representativeness or external validity of the model. The surveys may not be internally valid in that some differences can be explained away as artifacts of the survey itself, e.g. the process of interviewing may produce "reactions" with the respondents which invalidate the responses (cf. Campbell and Stanley, 1963; Webb et al., 1966; Kerlinger, 1964).

Milburn (1971) employs a criterion of policy relevance similar to the multiple streams of evidence rule of this essay. He states that in utilizing scientific data in the policy process it is important to use multi- 
method research strategies. From experimental design considerations, multimethod research strategies insure that empirical support for a model is not merely a function of the researcher's expectations or the method employed in testing it. Milburn also points out that research based on multiple streams of evidence or different methods of validation is well-suited to the diversity of backgrounds found among policy analysts. They may have been historians, area specialists, or behaviorally oriented social scientists before entering the government. Models validated with various methods and types of data, therefore, have a good chance of being accepted by policy analysts. ${ }^{7}$

With the control and confidence criteria as guides, this essay performs a critical evaluation of the policy relevance of various types of models. The essay makes an effort to pinpoint those models which offer promise for using social science products in government. The control and confidence criteria are not exhaustive of the criteria that could be used in identifying policy relevant models. The control and confidence criteria describe conditions that may enable a model to bridge the gap between social science and government. It is not necessary for both criteria to be satisfied for a model to be policy relevant to some degree; it may be

7. Again if there were theories of world politics developed already, there would be less need for multiple streams of evidence, but rather more need for an economy of evidence. In the present state of the model building enterprise, however, it is necessary to employ multiple streams of evidence to decrease threats to valid external inferences and thereby increase the confidence policy makers have in the resulting model. In model building one often makes an effort to construct and confirm a pattern of statements applicable across time and space. $A$ model based on multiple streams of evidence insures that a particular model is more general than the situation specificity of models that depend on only one stream of evidence. that only one criterion is met in a given situation.

Imagine a model in which a policy maker has confidence because it: (1) combines deductive power with empirical applicability; (2) is based on multiple streams of evidence; but (3) does not employ manipulable variables. This model might permit one to forecast with high confidence the fluctuation in a variable over which one has no control regardless of cost. This forecast might allow a policy maker to make plans which, although not affecting the variable in question, might mitigate its effect. For example earthquakes often are not predictable in advance. Nonetheless, areas where they frequently occur have developed standard operating procedures for processing the injured, alleviating congestion, and communicating in the absence of normal channels. Similarly, international crises may not be predictable in advance. Yet governments may set up standard operating procedures for decision making and implementation in the event of crises. For example, the Washington Special Action Group (WSAG) of the United States National Security Council is an interagency group for crisis decision making and implementation. Thus if an event such as an earthquake or an international crisis cannot be stopped or changed, vulnerability to it may be decreased through the development of standard operating procedures.

Prior reviews of the literature of ten focus on the confidence criterion but give little attention to the control criterion of policy relevance. For example, Snyder's (1962) excellent review of trends in the world politics literature deals with deductive and inductive styles but provides little insight into the policy relevance of these approaches. In addition, Robinson's (1970) perceptive critique of the literature on crisis decision making focuses on concepts, models, hy- 
potheses, and techniques of analysis. Although Robinson deals explicitly with the policy process and is thus policy relevant in a general sense, his essay does not employ the control criterion of policy relevance used in this essay. Whiting (1970) provides a further contribution regarding policy processes in general but may not be policy relevant according to the control criterion of this essay. Whiting suggests that the tasks of the political scientist are "... to determine the [policy] process, to discover its shortcomings, and to designate means of improvements" (p. 34). Only if the research on the policy process yields models whose variables are relatively manipulable, for example, would the Whiting suggestion result in policy relevant research according to the control criterion of this essay.

Thus far this essay implies that closing the gap between social science research and government policy depends basically on the research meeting various policy relevance criteria. It is essential to note that the relationship between research and policy also depends upon the state of the policy process. Quite different tasks face policy analysts and policy influencers as a policy problem progresses from one stage to another. There are variations in what is policy relevant depending upon the particular phase of the problem. Hermann (1971) creatively outlines five more or less prominent analytical stages of the policy process. These stages include (1) problem recognition, (2) problem and option definitions, (3) option advocacy, (4) implementation, and on occasion (5) evaluation. These policy stages and the outputs from the social sciences that are relevant at each stage are summarized in Table 2. The model building efforts to be discussed, to the extent that they are relevant according to the proposed criteria, are probably most useful to the policy analyst in the first three of Hermann's stages. An attempt will be made to indicate to what stage of the policy process each model building effort is most applicable.

Some illustrations of models in world politics from the perspective of their policy relevance follow. There is no pretense at completeness in the evaluation; rather the models selected are illustrative of broad trends. Models based on game theory and experimental games, man-machine simulations, aggregate data, and computer simulations and information systems constitute the categories for evaluation.

\section{Policy Relevance of \\ Game Theory Models and Experimental Games}

Game theory involves several models. The model of zero-sum games is the most formally developed mathematically. This model has been frequently criticized as not being applicable to most bargaining situations because it assumes that the players' interests are directly antithetical. What A wins, B loses, and vice versa.

Riker (1962) developed a zero-sum model of coalition behavior. In addition to the zero-sum situation Riker assumes rationality and perfect information, among other limiting conditions, to deduce the size principle: coalitions tend to be of minimal size necessary to win. Critics of Riker of ten attack the zero-sum assumption as being unrealistic in relation to world politics. Nevertheless, Riker's model yields an empirically testable proposition concerning the minimal size of coalitions. According to the control and confidence criteria of this essay, Riker's model comes off with a relatively high rating.

The assumptions of Riker's model generally are not under the control of policy makers, e.g. one can rarely perceive that he can manipulate the zero-sumness of a strategic situation. Moreover, there are limita- 
TABLE 2

HERMANN'S POLICY-MAKING STAGES*

\begin{tabular}{ll}
\hline Stage & Kinds of inputs from social sciences \\
\hline 1. Problem/task recognition & Case studies \\
& Description accounts \\
& Projections and forecasts \\
& Historical analogies \\
& Trend analysis \\
& Data banks \\
2. Problem and option definition & Systems analysis \\
& Multivariate analysis \\
& Partial regression equations \\
& Anything that relates one option to an indicator of policy \\
& objectives differently from other options-simple \\
3. Advocacy of options & correlations, tests of significant differences, simulations, \\
& or laboratory experiments \\
& Organizational and administrative studies \\
4. Implementation & Personnel selection procedures \\
& Survey research \\
& PPBS \\
& Social indicators \\
5. Evaluation & Definitions of policy outputs \\
& Comparative case studies \\
& Item construction \\
& Scaling techniques \\
\hline
\end{tabular}

*Constructed from Hermann (1971). Hermann's complete table includes bureaucratic concerns, conditions increasing receptivity to research, and channels for transmitting social science inputs for each stage of the policy process.

tions on the degree to which policy makers can make rational decisions, and thus the model's assumption of rationality may not be subject to control. On the other hand an implication of Riker's model may be perceived as manipulable, e.g. the extent to which policy makers decide to include additional members in their coalition.

With respect to confidence, Riker's model receives a high mark for deductive power with empirical applicability but a lower rating for multiple streams of evidence. Given his assumption the size principle follows according to rules for valid inference-illustrating deductive power. The size principle itself has high empirical applicability. Riker and his colleagues illustrate the size principle in different situations of coalition formation, including experimental games, political parties, and international empires (also cf. Groennings, Kelley, and Leiserson, 1970). The wide range of empirical materials in which they illustrate the size principle results in a moderate mark on the multiple streams of evidence criterion.

A lack of concern with experimental design criteria, however, mars much of the research on the size principle. There often are inadequate controls for extraneous variance in designing tests of the size principle; thus there are several rival hypotheses which also may explain the size principle besides the Riker model. Nevertheless, Riker's model probably ranks at the top of game theory 
models on the basis of the control and confidence criteria of this essay.

Where Riker's model assumes a zero-sum situation, there are non-zero-sum models that may be less policy relevant in certain respects, but more relevant in other respects. For example, a non-zero-sum model often loses logical closure and thus deductive power. The non-zero-sum assumption on the other hand is a closer approximation to bargaining situations in world politics. That is, a typical situation in world politics is where actors have both competitive and cooperative interests. Thus the non-zero-sum model ranks lower on deductive power but higher on empirical applicability than the zero-sum model. Regarding the control criterion of policy relevance, the non-zero-sum and zero-sum games seem equal. Where the assumptions in the models themselves may not be perceived as highly manipulable, the models' implications may be thought of as manipulable. One way of exploring implications of a game theory model is to use experimental gaming.

Schelling (1961) states that the reason one uses experimental games is that game theory is inadequate by itself in a study of bargaining processes. He concludes that experimental games contain an element of indeterminacy that better reflects the world than game theory alone. Rapoport (1960), moreover cautions against the misinterpretation of experimental evidence regarding game theory: "... classical game theory is not based on experimental evidence. It represents an attempt to build a normative theory on a foundation of strategic logic" (p. 224, emphasis in original). Experimental gaming nevetheless might provide some evidence for or against the implications of deductive models. The Journal of Conflict Resolution contains much of the literature on experimental gaming, some of which is set within the context of non-zero-sum game models. The Prisoner's Dilemma experiments, for example, constitute an important set of studies in this literature.

Game theory provides a formal deductive base for experimental gaming. A policy maker can have some limited confidence in these experiments based on game theory since they are illustrative of an initial attempt to combine deductive power with empirical applicability (e.g. the experiments). Confidence in game theory models, however, is lowered if laboratory evidence is the only type of evidence for evaluating the implications of the models. These experimental studies sacrifice external validity (generalizability) for internal validity (tight controls to eliminate rival hypotheses).

Generalizing the results of experimental games to domestic or international political situations can be misleading. A laboratory setting can place serious constraints on the realism of the situation invoked. For instance, many game situations neglect the psychological make-up of the participants, which may be of importance in determining outcomes. As Rapoport (1960) notes, there is more to winning a game than simply the amount in the pot. "There is the jingling of the coins, the admiration of the onlookers, the feeling of being lucky, etc." (p.121).

Rapoport (1968) states that there is a great deal to be learned about the dynamics of interaction through the playing of experimental games. He believes, however, that it is too early to raise the question of the applicability of the results of these mixedmotive games to mixed-motive conflicts in world politics. Hasty extrapolation may lead to faulty conclusions or perhaps to forsaking the laboratory games for more "realistic" arrangements. "What is worse, viewing the laboratory methods in terms of simulation of real life conflicts leads to designs which are not guided by the inner logic of a systematic investigation" (p. 469). Only 
when the empirical generalizations have become stabilized into a model of the $2 \times 2$ game situation should the relation to international conflicts be considered. There is also a limited range of results that can be obtained in any set of experimental game situations. For example, Rapoport (1968) notes that thousands of experiments must be performed to collect a data base that can yield a description of how the choices in a Prisoner's Dilemma $2 \times 2$ game are influenced by the payoffs.

Some of the basic independent variables that are used in experimental gaming are the payoff matrix, time, characteristics of the players, and the strategy of the other player. Returning to Kent's criterion, can any concrete decision problem be imagined in which the findings of a game theory model might affect the policy choice that would be made? In this regard, the most interesting findings may concern the various strategies used in the game. Strategic behavior may be one of the most manipulable variables for a policy maker. In an international bargaining situation it is not usually possible to manipulate time or the characteristics of the other participants, but it may be possible to manipulate the strategy used for one's own nation and the payoff matrix. One interesting and consistently reported laboratory finding is that simple contingent strategies (particularly a tit-for-tat strategy on the part of the experimenter's confederate), tend to push the subject toward cooperation (Rapoport, 1968). When faced with a choice between cooperative or competitive strategies in an international conflict situation, policy makers at least should be aware of the long-term prospects for motivating their opponent to reciprocate cooperatively.

Experimenters design $2 \times 2$ game situations in such a tight fashion that the game's generalizability must suffer. The process of validation occurs partly through manipulating a selected number of independent variables and assuming that all other variables are either controlled or randomly distributed. The obvious problem is that in an international bargaining situation it may be impossible to control these variables or to assume that they have an unbiased distribution. Most models used in experimental gaming do not fit the empirical situation and thus decrease the confidence a policy maker will have in their implications. The models may orient the policy maker to evaluate his problem in different terms, and they may suggest new perspectives from which to view the policy situation, but they also may mislead the policy maker (cf. Wilson, 1968).

With reference to Table 1 , the information provided by a scholar who uses game theory models may be useful to the evaluator or the diagnostician. Game theory, despite its usual level of abstraction, has been extremely helpful in the formulation of problems and the clarification of concepts (Schelling, 1963). Game theory models and experimental gaming also might be useful to the planner or the operator. These users are motivated by the need for substantive information such as options, costs, and benefitsboth foreign and domestic. Game theory models might be most helpful to these users in the problem/task recognition stage or the problem and option definition stage of the policy process (see Table 2). These stages consist of periods of search for information about a problem and possible responses to it that are unbiased by previously determined policy options.

In summary, game theory models and experimental games score relatively well on the criterion of control, but a policy maker should view them with mixed confidence. That is, some models combine deductive power with limited empirical applicability, but the game's inferences may suffer from inadequate attention to the multiple streams of evidence criterion. 
Policy Relevance of

\section{Man-Machine Simulations}

There are other laboratory studies not tied as much to game theory as some of Riker's and Rapoport's work. These other studies sacrifice additional logical closure of the deductive game model for more empirical applicability. Shure and his colleagues (Shure, Meeker, and Hansford, 1969), for example, have studied bargaining situations with more face validity regarding world politics than the simple Prisoner's Dilemma experiments. Like the Prisoner's Dilemma bargaining situations tied more closely to game theory, the Shure studies deal with manipulables and thus address one policy relevance criterion successfully.

For example, Shure and his associates manipulated the experimental conditions related to the character of a pacifist via a simulation design. They also manipulated the communication network and provided the opportunity for direct exchanges of messages above and beyond that information communicated by overt game moves. The experiment also provided for the unwarranted use of power at any time during the game situation. The Shure et al. studies thus deal with variables that could be manipulated by policy makers if the results of bargaining experiments were extrapolated to international bargaining situations. The Shure et al. experiments grew out of an earlier series of studies that concerned threat availability and psychological factors in conflict escalation. The authors found that the pairing of a cautious well-intentioned bargainer with an aggressive bargainer led to greater loss and disruption than that occurring between pairs of equally matched partners. The simulated pacifist studies were done in an effort to identify those features of bargaining that prove to be beneficial or detrimental in the realization of a cooperative bargaining outcome.
These studies illustrate a limited attempt to build models in which a policy maker could have confidence. That is, they combine a limited deductive power with empirical applicability. They seem to be great departures from formal game theory because of the relaxed assumptions necessary to construct the bargaining situation. These models however are an example of an attempt to gain policy relevance using the results of empirical investigations to modify the more deductively oriented experimental bargaining games of the Rapoport variety. Although the propositions tested in the Shure et al. studies are not explicitly drawn from formal game theory, the information gained might be useful in future model building because it systematically reflects some of the conditions of an international bargaining situation.

Laboratory studies, such as these manmachine simulations, introduce even more complexity into the situation than the simple experiments in order to gain additional external validity. A man-machine simulation generally combines human functioning in political and economic roles with computer programs or other constraints on their activity. In a typical man-machine simulation run, a large number of subjects are grouped into fictitious nations in a laboratory representation of certain aspects of world politics (cf. Guetzkow et al., 1963). Such aggregations allow for the study of more macrolevel processes as alliance cohesion and warfare.

For example, an important tentative finding from one man-machine simulation study (Brody, 1963) is that after the spread of muclear weapons, the former nonnuclear nations may be more likely to communicate outside their own bloc than before. That is, bipolarity tended to give way to multipolarity after the spread of nuclear weapons. Were there more evidence in favor of Brody's finding, it is possible to imagine a decision problem where his tentative finding 
might affect the choices to be made. For example, long-range planners in international security affairs speculate about the structure of the international system for which proposed weapons systems are to be constructed. If these planners suspected that the weapons systems themselves might affect the structure of the international system, their choices might be quite different than is the case presently.

As noted above, what the man-machine simulations gain in a closer approximation of international situations they often lose in precision and deductive power. These simulations, however, are not without some closure gained through the introduction of an explicit model which operates as a representation of international processes. The operation of a man-machine simulation model produces consequences which are implications of the programmed constraints and the behavior of individuals who may be participating. The consequences however are not calculable in advance as with a deductive model such as Riker's since the variables in the simulation interact in an unknown way. Hundreds of interactions produce consequences of an indeterminate nature.

Man-machine simulations vary in how they meet the confidence criterion of multiple streams of evidence. A policy analyst, for example, may have little confidence in the Shure et al. experiments, because like other laboratory studies they draw solely on experimental data. There is little attempt to validate the laboratory based conclusions using data from such arenas as arms control negotiations. On the other hand, Harold Guetzkow and his colleagues have found some correspondence between their simulations and empirical material drawn from a variety of different data bases (Guetzkow, 1968; Hermann and Hermann, 1969). As a result, the policy relevance of their InterNation Simulation and related models is greater than that of the simple laboratory experiments (cf. Coplin, 1968; Coplin, Mills, and O'Leary, 1971). ${ }^{8}$

The man-machine simulations exceed the simple laboratory studies in the sheer number of manipulables available, and thus at first blush may rank ahead of the latter on this policy relevance criterion. There may be design problems in a model with many manipulables, however. Parsimony dictates an economy of indicators in the model building enterprise, although a variety of types of evidence is necessary to gain external validity. In addition, the multiplicity of variables in man-machine simulations lowers the internal validity because of the inability to isolate causal processes from extraneous forces.

In summary, man-machine simulations score relatively well on the control criterion of policy relevance, even though too many manipulables may create some difficulties. These simulations vary as to how well they meet the confidence criterion. In general the models attempt to combine limited deductive power with empirical applicability. The studies evaluated above lose policy relevance as they sacrifice logical closure, but gain relevance as they become more empirically applicable. Considering the second half of the confidence criterion, some man-machine simulations have been partially validated using multiple streams of evidence, while others are still tied only to one source.

As with the models based on experimental gaming, man-machine simulation models could probably be most useful in the problem and option definition stage of the

8. Coplin, O'Leary, and Mills developed a simulation called PRINCE which is a man-computer simulation providing representation of a hypothetical foreign policy environment for a participant assuming the role of a policy maker. PRINCE allows the participant to explore the risks, costs, and benefits to foreign policy leaders as they pursue various strategies. Although PRINCE has some "face validity," as of this writing, it remains to be validated systematically. 
policy process ( see Table 2). To the operator or the planner at this stage, models with manipulables provide for the formulation of alternative responses to a problem (see Table 1). Models which meet the control criterion also may aid in recognizing and structuring the policy problem ${ }^{9}$

\section{Policy Relevance of Aggregate Data Models}

Laboratory studies constitute one strategy for model building; aggregate data studies represent another basis for model building. Although the great quantity of aggregate studies are mainly inductive in their orientation, there are some deductive type models that yield empirically testable implications about world politics. The arms race literature abounds with illustrations of studies employing a deductive strategy of modelling. Based on a fundamental model set forth by Richardson (1960a), the arms race studies are at once theoretically significant and policy relevant. The theoretical and policy nature of the Richardson process model derives from its assumptions concerning the conditions under which defense planners increase or decrease the level of their armaments:

(1) Defense planners will predicate changes in their armaments based upon some constant proportion of their opponent's armaments.

(2) Owing to the expense of maintaining arms, they will decrease at some constant proportion of the existing force level.

(3) Armaments will increase or decrease

9. The discussion above does not explicate the man-machine models themselves in the presentation of the simulations. For example the InterNation Simulation has a particular model of foreign 'policy decision making that emphasizes domestic constraints on policy while international system factors are unprogrammed. at a constant rate depending upon the dispositions defense planners have toward other countries, e.g. arms increase if there are feelings of hostility and decrease if there are feelings of amity.

(4) The above three conditions are additive.

Formally this can be modelled for the two-country case as:

$$
\begin{array}{ll}
\text { Country A } & \frac{d x}{d t}=k y-a x+g, \\
\text { Country B } & \frac{d y}{d t}=\ell x-b y+h,
\end{array}
$$

where $\mathrm{x}$ and $\mathrm{y}$ represent the armament expenditures for Country A and Country B respectively; $\mathrm{dx} / \mathrm{dy}$ is the rate at which Country A arms, while dy/dt is the corresponding rate for Country $B ; k$ and $\ell$ are the defense coefficients for each side respectively, e.g. the higher the $k$, the more Country $A$ is influenced by the amount of armament of Country $B$; $a$ and $b$ are the "fatigue and expense coefficients" and $g$ and $h$ are dispositions, e.g. hostility or amity.

Some consequences of these equations for the policy analyst are in their properties as a system of first order differential equations. Presumably the policy analyst would be interested in those conditions under which the system is in equilibrium, rather than those which would lead to an unlimited increase in the level of armaments. Logically the system would be in equilibrium when the rate of change of armaments would be zero for both sides. This occurs under the following condition:

\section{$\mathrm{k} \ell<\mathrm{ab}$}

which can be derived mathematically from the original set of equations. Note for instance that the dispositions for the two countries have no effect upon whether the 
system is stable or unstable, although they do determine the location of the equilibrium point.

A policy maker's initial reaction to this model might be to conclude that this form of social determinism leaves no room for rational policy choice; that is, once the coefficients are set, the process will lead to an unlimited increase in armaments (an impossibility) which will lead inevitably to war. Richardson himself inadvertently encourages such an interpretation by stating that the outcome of his model ". . . is what would occur if instinct and tradition were allowed to act uncontrolled" (1960a, p. 12; also cf. Rapoport, 1960 , pp. 15-107; 1957, pp. 249-99; Boulding, 1962; Smoker, 1969, (pp. 573-82), and McGuire, 1965).

As Richardson himself points out, however, it is one thing to describe a process in terms of a deterministic mathematical model as illustrated by equations, and quite another to conclude that policy makers have no freedom to alter the manipulables under their control and thereby dampen the arms race. The obvious manipulables in the arms race are the coefficients themselves. That coefficient most under the defense planner's control is the defense coefficient ( $k$ or $\ell$ ). By reducing this to zero and thus not reacting to his opponent, the defense planner unilaterally would preclude the possibility of an arms race. ${ }^{10}$ The dispositions are not readily manipulated by the defense planner, nor are the fatigue and expense coefficients.

Regarding the two criteria of policy relevance considered here-control and confidence-the Richardson model does relatively well. Having discussed control above (unilateral cessation of the arms race by setting one's rate of increase at zero), consider the Richardson model from the perspective of confidence: deductive power with empirical applicability and the use of

10. Thanks to Michael Mihalka for this interpretation. multiple streams of evidence in the model validation process.

The equations do yield deductive implications with high empirical import; hence the Richardson model should have consequences which command some of the confidence of policy analysts and defense planners. Richardson, however, restricts himself to defense expenditures as indicators of arms races and fails to employ multiple indicators of the arms process. Hence, the Richardson model receives only a moderate rating on the confidence criterion of policy relevance.

Arms race studies use aggregate data for the purpose of empirically validating deductive implications from mathematical models of the arms process. There are other studies that use aggregate data as evidence to test the implications of formal models. For example, the study of Olson and Zeckhauser (1968), "An Economic Theory of Alliances," uses a collective goods model to explain the sharing of defense costs within NATO. The deductive aspects manifest themselves in the derivation of empirically testable propositions from the collective goods model; the empirical aspects manifest themselves in the comparative statistical analysis across NATO member countries to test implications of the model.

A principal implication of the Olson and Zeckhauser model is the tendency for larger members of an alliance-those that place a higher absolute value on the public good-to bear a disproportionate share of the burden, e.g. alliance defense costs. As anticipated, the empirical tests find a positive correlation between the size of a member's national income and the percentage of its income devoted to the common defense. The model explains this finding, in part, from the fact that each ally must share the benefits of any additional increments of the collective good with all others while bearing the full marginal cost. Thus there is a strong incentive for any individual member to stop providing 
the collective good long before the group reaches a point of relative equality of burden sharing.

On the control aspect of policy relevance, the Olson and Zeckhauser study ranks high because it deals with defense expenditures, a variable that is relatively easy to manipulate. On the confidence criterion the study does moderately well. The model has deductive power through the derivation of empirically testable propositions and empirical applicability in the comparative statistical analysis across NATO member countries. The collective goods model is applied to a diverse set of empirical materials, thus addressing the multiple streams of evidence aspect of the confidence criterion of policy relevance.

The inductively oriented aggregate data studies are much more plentiful than the deductive strategies. The inductive studies often provide an opportunity for a clear demonstration of the control criterion of policy relevance: one can identify and rank the variables in the model as to their relative degree of manipulability. ${ }^{11}$ Consider a study using aggregate data by Kato (1969). Kato

11. Consider the following hypothetical example of an empirically oriented policy analyst suggesting a model to a policy maker who has already made his mind up to act with or without theoretical justification. Let the policy analyst present a model containing both manipulables and variables that are controllable only at high cost to the policy maker. Imagine that the "costly to manipulate" predictors explain some 80 percent of the variation while the easy to manipulate variables explain only 5 percent. The policy maker may ignore the variables that are too costly; when he does decide to take action, he may intervene via the factors that should have only about a 5 percent effect on the outcome. The policy analyst should warn the decision maker that he will not have the desired effect by intervening via factors that explain only 5 percent of the outcome variable. The policy maker's response might be as follows: to fire his analyst and state that, "Politics is the art of the possible-not the probable: Intervene where possible even if the desired outcome is not probable." (Tanter's First Law!) uses such variables as alliance affiliation, Communist threat, geographical location, and Soviet trade to predict US foreign aid allocations, having developed his theoretical expectations on the basis of a rational decision making model. In one of the regression analyses, he finds that geographical location is one of the better predictors and that Soviet trade is one of the poorest predictors of total US assistance allocated to a nation. Imagine that Kato, as an influencer of policy, presented his modelling to a Soviet policy analyst whose task it is to analyze trade as a counter to US influence in less developed countries. The respective policy maker probably would shrug his shoulders and proceed with business as usual when told that he is not likely to have an effect by intervening via trade. When confronted with no decrease in US assistance as a result of increased Soviet trade to a less developed country, his response may be to increase the level of trade to obtain the desired effect.

Regarding the confidence criterion, Kato creatively uses aggregate indicators to make inferences about unmeasured concepts characteristic of a rational decision-making model. The attempt to employ deductively oriented concepts and models and tap them through aggregate indicators places the Kato study near the midpoint of the deductiveinductive continuum, on the inductive side. Finally, Kato's study ranks low in multiple streams of evidence because he uses aggregate data exclusively. A policy analyst thus should have only moderate confidence in Kato's model and its implications.

The aggregate data models of Richardson, Olson and Zeckhauser, and Kato may be useful to a policy planner or operator in his delineation of policy options (see Table 1). Olson and Zeckhauser's model, for example, seems particularly relevant to the weighing of costs and benefits of alliance burden sharing alternatives. Richardson's model, in addition, would be useful to the policy 
scientist, who needs a model derived indicator system for estimation purposes.

Similarly, the aggregate data models relate to the problem and option definition stage of the policy process (see Table 2). They are also useful in Hermann's third stage, option advocacy. In this policy phase the range of options are narrowed and the question becomes one of choosing which of a small number of options has a more desired effect on the condition. In this stage the policy analyst seeks information that demonstrates a relationship between a variable present in one option and some indicator of the objective. Aggregate data models seem quite able to supply such information.

Once again, is there any concrete decision problem in which an aggregate data model could affect the choice made? Consider, for example, the Richardson type arms race model in relation to the Strategic Arms Limitation Talks (SALT) held in the late 1960s and early 1970s between the US and the Soviet Union. The SALT negotiations may be justified in part from an acceptance of Richardsonian thinking that the alternative to arms limitation is arms race. When the choice is perceived as mutual arms limitation or mutual escalation, as is suggested in Richardson models, proponents of arms control have an easier time influencing policy choice (cf. Scoville, 1972).

\section{Policy Relevance of Computer Simulation Models and \\ Information Systems}

Aggregate data also can be used in conjunction with computer simulation models. Where the simulation experiments discussed earlier consist of a man-machine interface, the work by Alker and Christensen (n.d.) is an all-machine or computer simulation, which has an aggregate data base. Their model of UN peacemaking success and fail- ure consists of: (1) a computer program that simulates the UN Charter to define UN involvement; (2) a formal process model of a precedent logic decision making procedure; (3) a statistical model for explaining and predicting UN success and failure on the basis of actual or hypothetical involvement roles; and (4) a set of mechanisms for revising operational expectations, procedures, or system rules.

The model operates through precedent search. Precedents are found by matching on the following five characteristics of disputes: existence of hostilities, UN organization involved (determined by the Charter), degree of major power involvement, type of issue, and period-general power configuration. The model also resolves conflicts in the simulation by providing for two measures of success: the extent to which the UN settles or helps to settle a dispute and the extent to which it stops hostilities.

An assumption of the Alker and Christensen model is uncertainty avoidance. The UN Charter is viewed as reducing uncertainty by specifying a behavioral repertoire of coercive and noncoercive events. Assumptions of organizational learning and forgetting also are employed in the model as Charter-based expectations are modified by experience. The authors state that if their model is a valid one, they can reconstruct prior histories and explore future possibilities.

The model partially meets the control criterion of policy relevance because it allows for varying the levels of involvement called for in the Charter and actually found in historical cases. Results of a related study by Alker and Greenberg (n.d.), using the model, suggest that the UN could have done better even while maintaining a limited type of veto, if participating states would have agreed to a more activist UN role. Admittedly, the UN Charter cannot be manipulated except at great cost. Charter reform, however difficult, does provide a potential policy 
influencer with an ultimate goal on which to focus his efforts.

The Alker and Christensen model receives some empirical support from aggregate data on collective security disputes before the UN in 1945-65. The model thus meets half of the confidence criterion of policy relevance-it has some deductive power with much empirical applicability. It may be more difficult to convince policy analysts of the relevance of an all-machine simulation because the model has not met the second half of the confidence criterion-multiple streams of evidence. That is, the model must be validated further with different types of data on the relevant disputes. This model, with its precedent search component, would be useful to the operator in problem solving or policy making as well as to the analyst in case comparison and system structure analysis (see Table 1). This computer simulation model could be most helpful in the problem and option definition or the option advocacy stages of the policy process (see Table 2).

Game theory and experimental games, man-machine simulations, aggregate data, and some computer simulations employ models that the scholar could adopt with more or less success (mostly less) in his effort to influence the affairs of state. A problem with many of these strategies is that they only address problem-solving and policy analysis functions in a limited way. For example, the Richardson process model intends first to be a contribution to theory; although it was important for Richardson personally, the policy aspects of his model are secondary to the theoretical contribution. Even then however the Richardson model still stands out as one of the most policy relevant ones considered. By computerizing its model, the Alker et al. simulation is a general improvement over the Richardson model. A related computer based strategy could be even more policy relevant than Richardson's model because of explicit attention to policy activities.

Bloomfield and Beattie (1971) were among the first to design a system around policy analysis functions and needs (e.g. the types presented in Table 1). They created a computer based model and information system: CASCON-Computer Aided System for Handling Information on Local Conflicts. CASCON provides policy planners and analysts with a computerized mechanism to help them manage local conflict situations. CASCON rests on a number of assumptions which together constitute a partial model of local conflict. The assumptions are as follows:

(1) Local conflicts have a general common structure rather than being always unique and random phenomena.

(2) All conflicts go through a preliminary dispute phase and one or more of three basic conflict phases-Phase I (dispute, prehostilities, premilitary), Phase II (prehostilities but dispute seen in military terms), Phase III (hostilities), Phase IV (posthostilities, but military option remains), Phase V (postconflict, but dispute remains), and Settlement of dispute.

(3) In each phase, factors can be identified that generate pressures tending to push the conflict across a threshold of transition into another phase. These factors may be countered by other factors that can be regarded as tending toward the prevention of that transition-or generally toward Settlement.

(4) Changes in the relationship among these specific factors will alter the likelihood of a conflict undergoing transition from one phase to another.

(5) The course of local conflicts can be significantly altered by policy measures aimed at reinforcing violence-minimizing factors and offsetting violence-generating 
factors, on the basis of "conflict-specific" factors identified for the phase in question.

CASCON addresses nicely the policy relevance criterion of control. Although a major power policy maker may have little or no control over the factors of a local conflict (e.g. the parties are historic enemies), they do have significant control over their policy measures which may affect the outcome of a local conflict. For example, one measure that can offset a conflict factor is to place stronger pressure on all parties to resolve the dispute bilaterally or accept compulsory third party settlement through international organization procedures.

CASCON does not score as well on the second criterion of policy relevance-confidence. Although it has empirical applicability, a policy maker may not have great confidence in its propositions because they are not logical consequences of an underlying deductive model. CASCON does employ a limited phase model of conflict; that is, CASCON assumes that any conflict passes through several stages. There is not however an explicit formal model underlying CASCON; rather it is basically an information storage and retrieval system designed to help the planner and analyst be creative in his work.

CASCON contains a data base of about 482 factors on 52 cases of local conflict. Government and area experts coded the factors for each case. In its present stage of development CASCON does not satisfy the multiple streams of evidence portion of the confidence criterion for policy relevance. CASCON developers, however, may expand the data base to include other types of substantive information such as event/interaction data.

CASCON permits a policy analyst to enter data into a computer terminal interactively for a new conflict during whatever phase is current. Later the analyst could retrieve the data. He then could compare a new case with the prior cases in the data base, and he could discover what possible policy measures were used or suggested in the prior cases. CASCON thus is useful to the analyst for case comparison (see Table 1). With its 52-case data base, CASCON meets an analysts's need for memory of actions and reactions of the foreign environment. Through the comparison of factors in various cases, CASCON also can aid the evaluator and planner in the identification of a potential new conflict.

The above discussion suggests that CASCON can be used in most stages of the policy process outlined in Table 2. CASCON may be useful in the problem/task recognition, problem and option definition, and advocacy of options stages, but it also may be directly applicable to the evaluation stage. CASCON affords a systematic comparison of prior cases on the factors involved in each conflict and the measures used in modifying each factor.

The author and his colleagues are developing a companion system to CASCON at the University of Michigan: CACIS-the Computer Aided Conflict Information System (see Tanter, 1972). Like CASCON, CACIS has an extensive retrieval system. CACIS, however, has more of a modelling capability than CASCON, with great stress on a process model of organizational decision making.

Similar to the Alker and Christensen computer simulation, CACIS relies on the concept of precedent search in its retrieval system. That is, a party in a conflict seeking a solution based on his goals, will search for historical precedents similar to the current one in order to obtain policy guidance. Precedent search behavior, moreover, assumes the existence of decision rules, e.g. criteria guiding the search, as well as the identification of dimensions of similarity and differ- 
ences along which one can locate conflicts. CACIS builds on and supplements CASCON'S pioneering lead. Whereas CASCON focuses on local conflicts between small powers or between small powers and only one major power participant, CACIS includes those conflicts involving more than one major power as well as the CASCON local conflicts. The CACIS design consists of separate yet interrelated modules which include the following: (1) a memory module which stores information about prior conflicts; (2) an experience module which stores evaluations on past strategies and outcomes; (3) an involvement or stakes module which provides information about the type and intensity of interests an actor has in a specific conflict; and (4) an operational environment module which includes information on both the international environment and the internal domestic policy making environment of the actors.

Several other computer simulations of domestic and international policy making environments also are being developed. For example McClelland and the World Event/ Interaction Survey (WEIS) group have used probablistic computer simulation models to reproduce past international event outputs of nations and project these into the near future. Probabilities of monthly nation event output frequencies and the probabilities of these events falling into certain classes are derived from the WEIS data base. These probabilities then become the basis of the computer simulation model. Within the model a random number generator selects from the probability distribution to produce a nation's simulated event output for any number of simulated months. The simulated output consists of the nation's simulated frequencies of various classes of actions.

One specific application of this model attempted to reproduce the past history of events targeted by the Soviet Union and the
United States toward one another, based on the probabilities of each nation issuing various types of action to the other observed in the WEIS data base. An effort was made to reproduce the degree of reciprocity in actual Soviet-US behavior. The McClelland group addressed the issue of mutual responsiveness of Soviet-American behavior in a creative fashion. They formulated three explanations of Soviet-American interactions. Each model tried to estimate parameters for input into a computer simulation to replicate SovietAmerican behavior for 57 months beginning in 1966. Model I generated output under the assumption that actual Soviet-American interactions were random, i.e., only connected by chance. Model II assumed that the behavior is perfectly reciprocal, while Model III posited bounded reciprocity. The McClelland group concluded that the limited reciprocal simulation model represented the historical Soviet-American interactions better than the random or perfect reciprocal model (McClelland, 1971, pp. 367-74).

Using the various computer simulations described above, a policy analyst could seek to establish and forecast behavior using a variety of models and test the various outcomes with prior and simulated cases. To the extent that these computer simulations are tied to an underlying model, policy makers may have some confidence in them. For the most part, however, the simulations are only loosely tied to underlying models, and they generally are bound to one type of data. Thus these simulations need continued development before they meet the deductive power with the empirical applicability aspect of policy relevance.

On the other hand, most of these computer simulations and information systems score well on the control aspect of policy relevance. These models deal with manipulables and present the policy analyst and planner with a range of possibilities within 
their control, both obvious and nonobvious. The computer simulation models may allow policy analysts to assess the interrelationships among policy options, and to test proposed options. These models could be helpful problem solving and policy analysis tools for most of the users listed in Table 1. For example, a policy analyst could use CACIS or WEIS to help determine a "nor$\mathrm{mal}$ " pattern of event/interaction between two nations. Deviations from the norm can alert the analyst that a change in relationship may be in the offing. These computer simulation models and information systems also may be a useful aid to the forecaster.

Recall the question of whether a decision problem can be imagined in which the findings of any of these computer simulations or information systems might affect the choice that would be made. For example, consider the Pakistani Civil War of 1971. How could one of the computer information systems affect policy choices at various phases of the civil war? The policy relevance of CASCON stands out in this regard. For the purpose of evaluating the utility of CASCON in on-going conflicts, the author commissioned experts (two Pakistani students) to code the civil and interstate, i.e. India-Pakistan, wars. Here are the results from the CASCON comparisons for relevant conflict phases.

In Phase I of the internal war, there are two cases that CASCON identifies as most comparable: ${ }^{12}$ Nigeria-Biafra (1967-70), and Venezuela (1960-63). To some analysts Biafra may seem an obviously comparable case. In both conflicts the dispute

12. Any two cases are comparable if either or both of the following is true: (1) Both cases have present many of the same factors, and the coding of these common factors does not show opposite effects (toward or away from violence); and (2) Both cases have many of the same factors not present. centered on a large disaffected group within the nation-the Ibos in Nigeria and the Bengalis in East Pakistan.

CASCON contains a factor labelled Ethnic-Minorities, Refugees. In this category Nigeria-Biafra and the Pakistan internal war are comparable. Within this category CASCON suggests that the following factors tended to push the conflict toward violence: (1) Large and powerful refugee groups and their supporters were created; (2) There was a long history of distrust between ethnic groups; (3) The impending emergence of an independent homogeneous state provided a focus for aspirations of similar people living elsewhere; and (4) Racial divisions within the disputed area favored the "non status quo" side. (In the Pakistan internal war the "non status quo" side is the Bengali separatists.) These four factors are by and large not subject to control by policy makers at the time of the dispute.

Venezuela (1960-63) is a less obviously comparable case, involving terrorist activity against the government in Venezuela. CASCON contains a factor category labelled Military Strategic, and one labelled Great Power Involvement. The factors within these categories are generally more manipulable than the factors in the Pakistani exampleEthnic-Minorities. Factors in common to Venezuela and the Pakistan Civil War, which tended to push the conflict toward violence, were the following: (1) Internal security forces of one side were inadequate to deal with the situation in the disputed area; (2) One side feared loss of disputed area would lead to loss of status; (3) Area was of strategic importance to one side; (4) One side had extensive training in guerrilla tactics. In addition, both the Pakistan and Venezuela cases had a factor in common which tended away from violence, that is, one side was militarily weak. All of these factors lend themselves to manipulation by 
policy makers. For example, Factor 1 above could be manipulated by giving aid to internal security forces. Factor 2 above could be manipulated by compensating the status quo side to offset a perceived loss of status. That is, the US could give aid for internal economic and social development and make sure such assistance prevented a loss of status.

The above discussion is a preliminary example of the application of CASCON to the problem of conflict management. When a policy analyst uses CASCON, he can be much more systematic in his comparison of cases and evaluation of factors. This example attempts to show that CASCON can be an aid to memory. It should be noted that the Nigeria-Biafra dispute culminated in hostilities, whereas the Venezuela dispute did not. The analyst dealing with the Pakistan Civil War would have wanted to identify the crucial differences between the Nigerian and Venezuelan disputes to prevent the Pakistan case from erupting into violence. (Further analysis is under way on the Pakistan-India war.)

\section{Summary and Conclusions}

Table 3 summarizes the policy relevance of the four types of models. All of the models discussed offer some hope for scholarly involvement in the policy process at one stage or another. The types of models used by Riker as well as by Olson and Zeckhauser seem particularly policy relevant according to the criteria in this essay. The design, development, implementation, and utilization of computer based models and information systems also offer a promising strategy for using social science products in government. Such a strategy, however, depends upon progress in other categories of model building such as game theory and experimental games, man-machine simulations, and aggregate data modelling. Drawing upon

TABLE 3

THE POLICY RELEVANCE OF MODELS IN WORLD POLITICS

\begin{tabular}{|c|c|c|c|c|c|c|c|c|c|}
\hline & \multicolumn{3}{|c|}{ Control } & \multicolumn{6}{|c|}{ Confidence } \\
\hline & \multicolumn{3}{|c|}{$\begin{array}{c}\text { Perceived } \\
\text { manipulability }\end{array}$} & \multicolumn{3}{|c|}{$\begin{array}{c}\text { Deductive power } \\
\text { with empirical } \\
\text { applicability }\end{array}$} & \multicolumn{3}{|c|}{$\begin{array}{c}\text { Multiple streams } \\
\text { of evidence }\end{array}$} \\
\hline & High & Med & Low & High & Med & Low & High & Med & Low \\
\hline \multicolumn{10}{|l|}{$\begin{array}{l}\text { Game theory models and } \\
\text { experimental games: }\end{array}$} \\
\hline Zero-sum games, Riker & & $\mathbf{x}$ & & $\mathrm{x}$ & & & & $\mathrm{x}$ & \\
\hline $\begin{array}{l}\text { Non-zero-sum games, } \\
\text { Rapoport }\end{array}$ & & $\mathbf{X}$ & & & $\mathrm{X}$ & & & & $\mathrm{X}$ \\
\hline \multicolumn{10}{|l|}{$\begin{array}{l}\text { Man-machine models and } \\
\text { simulations: }\end{array}$} \\
\hline Shure and others & $\mathbf{X}$ & & & & $\mathrm{X}$ & & & & $\mathrm{X}$ \\
\hline Guetzkow and others & & $\mathrm{X}$ & & & $\mathrm{X}$ & & & $\mathbf{X}$ & \\
\hline $\begin{array}{l}\text { Aggregate data models: } \\
\text { Richardson }\end{array}$ & & $\mathbf{X}$ & & $\mathbf{X}$ & & & & & $\mathbf{X}$ \\
\hline Olson and Zeckhauser & $\mathbf{X}$ & & & & $\mathrm{X}$ & & & $\mathbf{x}$ & \\
\hline Kato & & $\mathbf{X}$ & & & $\mathrm{x}$ & & & & $\mathrm{X}$ \\
\hline $\begin{array}{l}\text { Computer simulation models } \\
\text { and information systems }\end{array}$ & $\mathbf{X}$ & & & & $\mathrm{x}$ & & & & $\mathbf{X}$ \\
\hline
\end{tabular}


some of these complementary strategies, computer based models and information systems eventually may become even more policy relevant in terms of the control and confidence criteria of this essay.

Recall Guetzkow's statement regarding the scholar as policy influencer: "When the scholar is a policy influencer, he seeks to make application of simulations so that he may guide the affairs of states and international organizations in directions he values and wishes to achieve." From the incomplete overview of five categories of models and related tools, the author advises the policy influencer to consider the great potential of computer based models and information systems to help him guide the affairs of state. The risks are high that the policy influencer may be manipulated as he seeks to influence, but the cause of peace far outweighs the danger of losing one's scholarly independence.

\section{REFERENCES}

Alker, Hayward R. Supranationalism in the United Nations. In J. Rosenau (ed.), International Politics and Foreign Policy. New York: Free Press, 1969.

-- and Cheryl Christensen. From causal modelling to artificial intelligence: the evolution of a UN peace-making simulation. Unpublished manuscript, n.d.

--- and William T. Greenberg. The UN Charter: alternate pasts and alternate futures. Unpublished manuscript, n.d.

Axelrod, Robert. Conflict of Interest. Chicago: Markham, 1970.

Bloomfield, Lincoln P., and Robert R. Beattie. Computers and policy making: the CASCON experiment, Journal of Conflict Resolution, 1971, 15 (March), 33-53.

Bobrow, Davis B. Data banks, foreign affairs, and feasible change. Paper delivered at the Conference on Data Banks for International Studies, Washington, D.C., May 1971.

Boulding, Kenneth E. Conflict and Defense: $A$ General Theory. New York: Harper, 1962.
Brody, Richard A. Some systemic effects of the spread of nuclear weapons technology: a study through simulation of a multi-nuclear future, Journal of Conflict Resolution, 1963, 7 (4, Dec.), 663-753.

Burgess, Phillip. International relations theory: prospect 1970-1995. Paper presented at the Annual meeting of the American Political Science Association, Los Angeles, September 1970.

Campbell, Donald T., and Julian C. Stanley. Experimental and Quasi-Experimental Designs for Research. Chicago: Rand McNally, 1963.

Choucri, Nazli, and Robert North. Alternative dynamics of international conflict: population, resources, technology, and some implications for policy, World Politics, Supp. on Theory and Policy in International Relations, 1972, 24 80-122.

Copin, William D. (ed.). Simulation in the Study of Politics. Chicago: Markham, 1968.

-- Stephen L. Mills, and Michael O'Leary. PRINCE: participants guide to PRINCE, concepts, environments, procedures. Syracuse, N.Y.: International Relations Program, Syracuse University, September 1971 (mimeo).

Feierabend, Ivo K., Rosalind L. Feierabend, and Betty A. Nesvold. Social change and political violence: cross-national patterns. In Hugh Graham and Ted R. Gurr (eds.), The History of Violence in America. New York: Praeger, 1969, 632-87.

Frohlich, Norman, Joseph Oppenheimer, and Oran Young. Political Leadership and Collective Goods. Princeton, N.J.: Princeton University Press, 1971.

Gallup, George. As cited in Donald McDonald, Elmo Roper, and George Gallup, Opinion Polls: Interviews. Santa Barbara, Calif., 1962.

Galtung, Johan. Peace research: past experiences and future perspectives, Gandhi Marg: Journal of the Gandhi Peace Foundation, 1971, 15, (3. July): 185-200.

Groennings, Sven, E. W. Kelley, and Michael Leiserson (eds.). The Study of Coalition Behavior. New York: Holt, Rinehart, and Winston, 1970.

Guetzkow, Harold. Some correspondences between simulations and "realities" in international rela tions. In Morton Kaplan (ed.), New Approaches to International Relations. New York; St. Martin's Press, 1968, 202-69.

- - et al. Simulation in International Relations. 
Development for Research and Teaching. Englewood Cliffs, N.J.: Prentice-Hall, 1963.

Gurr, Ted R. A causal model of civil strife: a comparative analysis using new indices, American Political Science Review, 1968, 62, 1104-24.

---Why Men Rebel. Princeton, N.J.: Princeton University Press, 1970.

Haas, Michael (ed.). Peace Research. Chicago: Scott Foresman, in press.

Halperin, Morton. Why bureaucrats play games, Foreign Policy, 1971, (2, Spring), 70-90.

Hermann, Charles. The knowledge gap: the exchange of information between the academic and the foreign policy communities. Paper delivered at the American Political Science Association Convention, Chicago, September 1971.

-- and Margaret C. Hermann. An attempt to simulate the outbreak of World War I. In J. Rosenau (ed.), International Politics and Foreign Policy. New York: Free Press, 1969, 622-39.

Hilliker, Grant. Further development of data banks conference: discussion of decision functions and research. Mimeo, 1971.

-- - The transfer of knowledge into policy. Draft manuscript, 1972.

Isard, Walter (ed.). Peace Research Society Papers, $1970,12$.

Kato, Masakatsu. A model of US foreign aid allocation: an application of a decision-making scheme. In John Mueller (ed.), Approaches to Measurement in International Relations. New York: Appleton-Century-Crofts, 1969, 198-217.

Kent, George. The application of peace studies, Journal of Conflict Resolution, 1971, 15, (1, March), 43-53.

-- Prescribing foreign policy. Honolulu: Dimensionality of Nations Project, Report No. 59, January 1972.

Kerlinger, Fred N. Foundations of Behavioral Research. New York: Holt, Rinehart, and Winston, 1964.

Komer, Robert. Was there another way? Pacification as an alternate strategy in Vietnam. In Raymond Tanter (ed.), Limits of Strategic Intervention in Vietnam: US Policies, Programs, and Performance. 1973 (forthcoming).

Markus, Gregory B., and Raymond Tanter. A conflict model for strategists and managers. in Raymond Tanter (ed.), American Behavioral
Scientist (special issue), 1972, 15 (6, July/ August), 809-836.

McClelland, Charles A., et al. The Management and Analysis of Event Data: A Computerized System for Monitoring and Projecting Event Flows. Los Angeles: University of Southern California, 1971.

MoGuire, Martin C. Secrecy and the Arms Race. Cambridge, Mass.: Harvard University Press, 1965.

Milburn, Thomas. Increasing the perceived utility of science for policy makers. Paper delivered at the American Political Science Association Convention, Chicago, September 1971.

Milstein, Jeffrey, and William C. Mitchell. Computer simulation of international process: the Vietnam War and the pre-World War I naval races, Peace Research Society Papers, 1970, 12.

Neustadt, Richard. Alliance Politics. New York: Columbia University Press, 1970.

Nicholson, Michael. Conflict Analysis. New York: Barnes and Noble, 1970.

Olsen, Ole Jess, and Ib. Martin Jarvad. The Vietnam conference papers: a case study of a failure of peace research, Peace Research Society (International) Papers, 1970 15: 155-70.

Olson, Mancur, Jr., and Richard Zeckhauser. An economic theory of international politics. In Bruce Russett (ed.), Economic Theories of International Politics. Chicago: Markham, 1968.

Oppenheimer, Martin. The peace research game, Dissent, 1964, 11 (Autumn), 444-48.

Pilisuk, Marc. International Conflict and Social Policy. Englewood Cliffs, N.J.: Prentice-Hall, 1972.

Race, Jeffrey. American intervention abroad: systematic distortions in the policy-making process. In Raymond Tanter (ed.) Limits of Strategic Intervention in Vietnam: US Policies, Programs, and Performance. 1973, (forthcoming).

Rapoport, Anatol. Lewis F. Richardson's mathematical theory of war, Journal of Conflict Resolution, 1957, 1 (3,Sept.), 249-99.

---Fights, Games, and Debates. Ann Arbor: University of Michigan Press, 1960.

--- Prospects for experimental games, Journal of Conflict Resolution, 1968, 12 (4, Dec.), 461-70.

-- Can peace research be applied? Journal of Conflict Resolution, 1970, 14 (2, June), 277-86. 
Richardson, Lewis F. Arms and Insecurity: Mathematical Study of the Causes and Origins of War. Pittsburgh: Boxwood Press, 1960a.

-- Statistics of Deadly Quarrels. Chicago: Quadrangle, $1960 \mathrm{~b}$.

Riker, William H. The Theory of Political Coalitions. New Haven, Conn.: Yale University Press, 1962.

Robinson, James. Crisis decision making: an inventory and appraisal of concepts, theories, hypotheses and techniques of analysis. In James Robinson (ed.), Political Science Annual. Indianapolis: Bobbs-Merrill, 1970.

Rummel, Rudolph J. Some dimensions in the foreign behavior of nations. In J. Rosenau (ed.), International Politics and Foreign Policy. New York: Free Press, 1969.

Schelling, Thomas. Experimental games and bargaining theory. In Klaus Knorr and Sidney Verba (eds.), The International System. Princeton, N.J.: Princeton University Press, 1961.

-- Strategy of Conflict. New York: Oxford University Press, 1963.

Scoville, Herbert Jr. Arms limitation or arms race?, New York Times, 1972, (Feb. 24), 39.

Schmid, Herman. Peace research and politics, Journal of Peace Research, 1968, 3: 217-32.

Schwartz, David C. From political theory to peace policy: notes on a more structured research process, Peace Research Society (International) Papers, 1968, 11: 43-46.

Shure, Gerald, Robert Meeker, and Earle Hansford. The effectiveness of pacifist strategies in bargaining games. In John Mueller (ed.), Ap proaches to Measurement in International Relations. New York: Meredith Press, 1969, 99113.

Singer, J. David, and Melvin Small. National alliance commitments and war involvement, 1818-1945. In J. Rosenau (ed.), Intermational Politics and Foreign Policy. New York: Free Press, 1969, 513-42.
Smoker, Paul. Fear in the arms race: a mathematical study. In J. Rosenau (ed.), International Politics and Foreign Policy. New York: Free Press, 1969, 573-82.

Snyder, Richard. Recent trends in international relations theory. In Austin Ranney (ed.), Essays on the Behavioral Study of Politics. Urbana: University of Illinois Press, 1962, 103-72.

Society for the Psychological Study of Social Issues. Proposed position papers on research utilization in policy. Mimeo, n.d.

Tanter, Raymond. International system and foreign policy approaches: implications for conflict modelling and management. World Politics, Supp. on Theory and Policy in International Relations, 1972, 24, 7-39.

Wallace, Michael $B$. The radical critique of peace research: a non-evangelical interpretation. Paper presented to the Western Regional Peace Research Society (International) Conference, February 1971.

Webb, Eugene, et al. Unobtrusive Measures. Chicago: Rand McNally, 1966.

White, Ralph K. Misperception and the Vietnam War, Journal of Social Issues, 1966, 22 (3), 1-164.

Whiting, Allen S. Bureaucratic quicksand: the United States in Vietnam. Paper delivered at the American Political Science Association Convention, Los Angeles, September 1970.

-_- The scholar and the policy maker, World Politics (Supp. on Theory and Policy in International Relations), 1972, 24, 229-47.

Wilson, Andrew. The Bomb and the Computer. New York: Delacorte Press, 1968.

Young, Oran R. The perils of Odysseus: on constructing theories of international relations, World Politics, (Supp. on Theory and Policy in International Relations), 1972, 24, 179-203. 